\title{
2
}

\section{Epstein-Barr Virus-Positive Diffuse Large B Cell Lymphoma}

\author{
Motoharu Shibusawa $^{1} \cdot$ Keisuke Kidoguchi ${ }^{2}$ Tetsuya Tanimoto $^{3}$ \\ ${ }^{1}$ IMS group Shinmatsudo Central General Hospital, Department of Hematology, \\ Chiba, Japan; ${ }^{2}$ Saga-ken medical centre KOSEIKAN, Saga, Japan; ${ }^{3}$ Navitas Clinic Kawasaki, \\ Kanagawa, Japan
}

Author for correspondence: Motoharu Shibusawa, Shinmatsudo Central General Hospital, Department of Hematology, Chiba, Japan. Email: m_sibusawa@hotmail.com

Cite this chapter as: Shibusawa M, Kidoguchi K, Tanimoto T. Epstein-Barr Virus-Positive Diffuse Large B Cell Lymphoma. In: Gallamini A, Juwied M. editors. Lymphoma. Brisbane (AU): Exon Publications. Online first 2021 Nov 16.

Doi: https://doi.org/10.36255/exon-publications.lymphoma.2021.ebv-dlbcl

\begin{abstract}
Epstein-Barr virus (EBV)-positive diffuse large B cell lymphoma (DLBCL) is known for distinct clinical features. This disease was formerly designated as EBV-positive DLBCL of the elderly, but the restriction to elderly patients has been removed, and the World Health Organization classification revised 4th edition lists EBV-positive DLBCL, not otherwise specified (NOS). The frequency of EBV-positive DLBCL among DLCBL is about 2.5-14.0\%, with higher incidence among East Asians. Most cases occur in patients aged over 50 years old with male predominance. The clinical characteristics of EBV-positive DLBCL, compared to those with EBV-negative DLBCL, include association with older age, more advanced clinical stage, a higher rate of extranodal involvement, and worse performance status. It is usually treated with R-CHOP, consisting of rituximab, cyclophosphamide, doxorubicin, vincristine, and prednisone. EBV-positive DLBCL shows an inferior prognosis with R-CHOP as compared with EBV-negative DLBCL. Furthermore, high EBV-DNA load and positivity of EBV-encoded RNA in biopsy specimens are associated with a worse prognosis.
\end{abstract}

In: Gallamini A, Juwied M (Editors). Lymphoma. Exon Publications, Brisbane, Australia. ISBN: 978-0-6453320-0-1; Doi: https://doi.org/10.36255/exon-publications.lymphoma.2021

Copyright: The Authors.

License: This open access article is licenced under Creative Commons Attribution-NonCommercial 4.0 International (CC BY-NC 4.0) https://creativecommons.org/licenses/by-nc/4.0/ 
Keywords: diffuse large B cell lymphoma; differential diagnosis; EBV-positive DLBCL; Epstein-Barr virus; non-Hodgkin lymphoma

\section{INTRODUCTION}

The World Health Organization (WHO) classification published in 2017 defines diffuse large B-cell lymphoma (DLBCL), not otherwise classified as a neoplasm of medium or large B lymphoid cells whose nuclei are the same size as or larger than those of normal macrophages, or more than twice the size of those of normal lymphocytes, with a diffuse growth pattern (1). Globally, the estimated number of new cases with non-Hodgkin lymphoma (NHL) was 509,600 in 2018 (2). Regarding the subtype of DLBCL, it is estimated that there are 150,000 new cases annually worldwide (3). A subset of DLBCL is linked to Epstein-Barr virus (EBV), which is the focus of this chapter.

DLBCL is the most frequent lymphoma subtype, accounting for $31 \%$ of all lymphoma subtypes (4). Patients with DLBCL usually present with rapidly enlarging lymphadenopathies, and about $40 \%$ of DLBCL cases have extranodal sites at the time of initial presentation. Extranodal sites can include the gastrointestinal tract, bones, testes, spleen, Waldeyer ring, salivary glands, thyroid, liver, kidneys, and adrenal glands. B symptoms may be present (1). The Ann Arbor staging system is usually used for staging (5). Chromosome abnormalities and gene mutation can be detected. The standard therapy for DLBCL is an immunochemotherapy regimen called R-CHOP, consisting of rituximab, cyclophosphamide, doxorubicin, vincristine, and prednisone (3). As prognostic models, International Prognostic Index (IPI), revised IPI (R-IPI), and National Comprehensive Cancer Network IPI (NCCN-IPI) have been known (6).

Although DLBCL is a highly heterogenous neoplasm, gene expression profiling classifies DLBCL into the germinal center B-cell-like (GCB) subtype and the activated B-cell-like (ABC) subtype (3), with the frequency of $56.4 \%$ for GCB, $32.2 \%$ for $\mathrm{ABC}, 11.3 \%$ for unclassifiable (7). The GCB subtype DLBCL is considered to be derived from lymphoid cells in the germinal center. The GCB subtype expresses $\mathrm{CD} 10, \mathrm{LMO} 2$, and the transcriptional repressor BCL6, and EZH2, which are normally detected in germinal center B-cells. On the other hand, the $A B C$ subtype is considered to be derived from $B$ cells at a plasmablastic stage. The $A B C$ subtype expresses genes that are frequently expressed in mature plasma cells. The ABC subtype is characterized by activation of nuclear factor kappa B (NF-kB) $(3,8)$.

Moreover, there are several types of large B-cell lymphomas. The WHO classification in 2017 lists other large B cells lymphomas as follows: T-cell/ histiocyte-rich B-cell lymphoma, primary DLBCL of the central nervous system (CNS), primary cutaneous DLBCL leg type, EBV-positive DLBCL, not otherwise specified (NOS), DLBCL associated with chronic inflammation, lymphomatoid granulomatosis, large B-cell lymphoma with IRF4 rearrangement, primary mediastinal large B-cell lymphoma, intravascular large B-cell lymphoma, ALK-positive large B-cell lymphoma, plasmablastic lymphoma, HHV8-positive DLBCL, and primary effusion lymphoma (1). 


\section{NATURAL HISTORY OF EPSTEIN-BARR VIRUS INFECTION}

EBV is a gamma herpesvirus and primarily targets B lymphocytes. EBV infection is prevalent in humans worldwide. Exposure to the virus usually occurs early in life, and the virus is transmitted commonly through oral secretions. More than $90 \%$ of people are infected, and the infection lasts for life-long. The natural history of EBV infection is shown in Figure 1.

EBV infection has two distinct phases: primary infection and latent infection. In healthy children, primary EBV infection is typically asymptomatic. However, infection in adolescence can present with infectious mononucleosis $(9,10)$. In primary infection, EBV infects epithelial cells and/or B-cells in the oropharynx. When EBV infects, virus replication starts, and then EBV lyses the infected cells (lytic replication). The infection of B cells by EBV results in latent infection (10). To explain the mechanism of latent infection in detail, most EBV-infected B-cells are eliminated by cytotoxic $\mathrm{T}$ cells and NK cells through the antigen-specific T-cell response, but some EBV-infected B cells escape by downregulating antigen expression. Then, they pass through the germinal center and subsequently exit as EBV-infected memory cells (latent infection). Thus, immune T-cell surveillance has a crucial role in controlling persistent EBV infection (10-12).

The EBV genome consists of a linear DNA molecule that encodes nearly 100 viral proteins (10). The patterns of gene expression have different characteristics between primary and latent infection. In primary infection, EBV-infected B-cells express the full complement of viral proteins. This expression form is called Latency III; six Epstein-Barr nuclear antigens (EBNAs 1, 2, 3A, 3B and 3C and

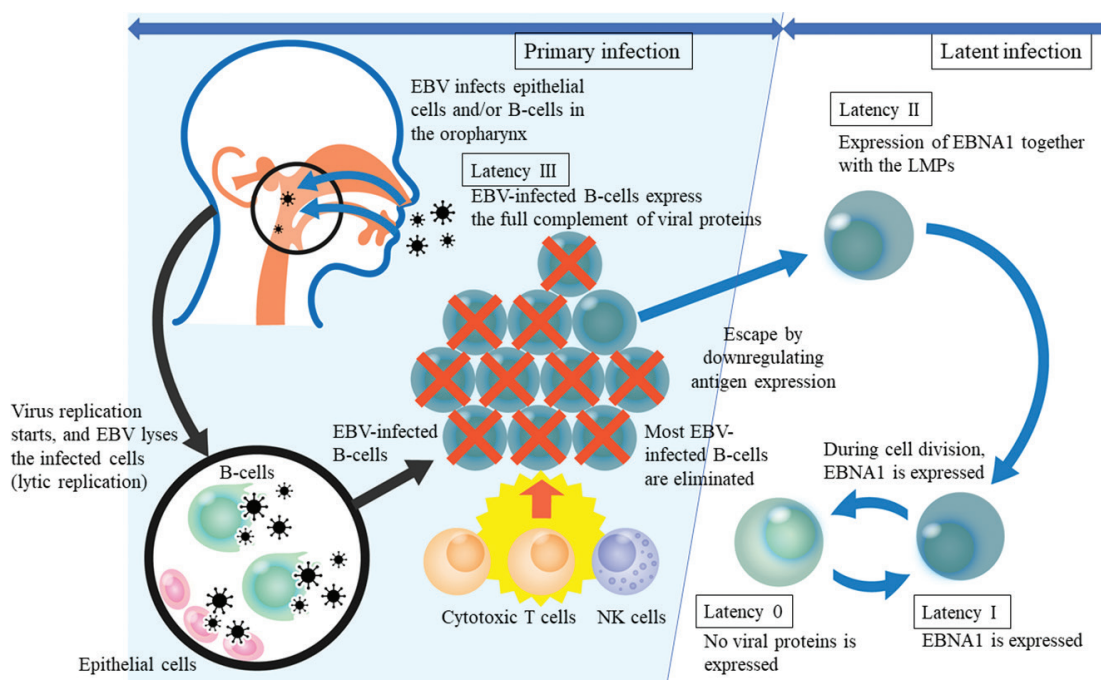

Figure 1. Natural history of Epstein-Barr virus. In primary infection, EBV infects epithelial cells and/or B-cells in the oropharynx. When EBV infects, virus replication starts, and then EBV lyses the infected cells (lytic replication). Most EBV-infected B-cells are eliminated by cytotoxic T cells and NK cells through the antigen-specific T-cell response, but some EBV-infected B cells escape by downregulating antigen expression. EBV-infected B cells exist as memory B cells (latent infection). EBV, Epstein-Barr virus. 
EBNA leader protein), latent membrane proteins (LMP1, 2), EBV-encoded RNA (EBER), and viral microRNA. On the other hand, EBV-infected memory cells express no viral proteins (an expression form called Latency 0), but during cell division, EBNAl is expressed (an expression form called Latency I). An expression form called Latency II is characterized by expression of EBNAl together with the LMPs (12).

\section{EBV-POSITIVE DLBCL}

There are some B-cell neoplasms linked to EBV infection, and the oncogenic mechanisms of EBV are considered to be predominantly attributable to LMP1 (8). These tumors are characterized by malignant B-cells that frequently express EBV transcripts and proteins indicating EBV infection. B-cell neoplasms linked to EBV infection include DLBCL, post-transplant lymphoproliferative disease, Burkitt lymphoma, primary CNS lymphoma, plasmablastic lymphoma, and primary effusion lymphoma (13).

EBV-positive DLBCL is listed in the WHO classification in 2017 and is known for its distinct clinical features. The WHO classification firstly listed this disease as EBV-positive DLBCL of the elderly in 2003. Subsequently, it listed EBV-positive DLBCL of the elderly (provisional entity) in the 2008 WHO classification (8). However, the restriction to elderly patients has been removed, and the WHO classification in 2017 lists EBV-positive DLBCL, NOS.

The WHO classification defines that EBV-positive DLBCL, NOS is an EBVpositive clonal B-cell lymphoid proliferation. Excluded from this category are cases of lymphomatoid granulomatosis, a case with evidence of acute or recent EBV infection, other well-defined lymphomas that may be EBV-positive (such as plasmablastic lymphoma and DLBCL associated with chronic inflammation), and EBV-positive mucocutaneous ulcer (localized EBV-driven proliferations affecting cutaneous or mucosal sites) (14).

\section{EPIDEMIOLOGY}

The racial and ethnic distributions of the incidence of NHL per 100,000 individuals (men and women) vary as follows: 25.0 and 17.0 for White, 10.8 and 10.9 for American Indians, 16.5 and 11.1 for Asian/Pacific Islanders, 17.7 and 12.5 for African Americans, 20.9 and 15.9 for Hispanics. Thus, the incidence of NHL is high in White and Hispanics. Moreover, there are some subtypes of NHL that vary widely in the incidence among race/ethnicity and regions. Specifically, mycosis fungoides show a higher incidence among African Americans. Adult T-cell leukemia/ymphoma shows higher incidence in Japan, West Africa, and the Caribbean. Furthermore, Burkitt lymphoma associated with EBV has a higher incidence in Africa (2).

\section{Epidemiology of DLBCL}

The distribution of the age of onset of DLBCL is as follows: $4.5 \%$ ( $<30$ years old), 9.7\% (30-39 years old), 13.0\% (40-49 years old), 24.2\% (50-59 years old), 
28.9\% (60-69 years old), 17.5\% (70-79 years old), and 1.8\% ( $\geq 80$ years old). Thus, the frequency is highest in the 60s of age. Moreover, the percentage of men (55.2\%) was higher than that of women (44.8\%) (15).

Risk factors associated with the development of DLBCL have been reported (15). The presence of a family history of NHL is associated with the development of DLBCL (odds ratio, 1.95). Occupational risk factors include field crop/vegetable farm worker, women's hairdresser, and seamstress/embroider (odds ratio: 1.78, 1.65 , and 1.49, respectively). Risk factors associated with medical history include B-cell activating autoimmune diseases, hepatitis C virus seropositivity, higher young adult body mass index (odds ratio: 2.36, 2.02, and 1.58, respectively) (15). Furthermore, infection of human immunodeficiency virus (HIV) and human herpes virus 8 is predisposed to $\operatorname{DLBCL}(2,16)$. However, there are no previous reports that EBV increases the incidence of DLBCL.

\section{Epidemiology of EBV-positive DLBCL}

Oyama et al. reported 96 patients with EBV-positive B-cell lymphoproliferative disorders (LPDs) mainly consisting of DLBCL (EBV-positive DLBCL group), compared them with the EBV-negative DLBCL group of 107 patients aged over 40 years with EBV-negative DLBCL (17). In their study, the diagnosis of age-related EBV-associated B-cell LPDs was made when more than $50 \%$ of the proliferating cells showed both the expression of one or more pan-B cell antigens (CD20/CD79a) and/or lightchain restriction and positive EBER on paraffin section.

The median age among the EBV-positive DLBCL group was 71 years old (range: 45-92 years), and the percentage of patients aged $\geq 60$ years was $82 \%$, while among the EBV-negative DLBCL group, the median age was 62 years old (range: 41-85 years), and the percentage of patients aged $\geq 60$ years was $52 \%$. EBV-positive DLBCL group were significantly older than those with the EBVnegative DLBCL group. The male to female ratio of the EBV-positive DLBCL group was 1.4, which was not different from that of the EBV-negative DLBCL group (17).

Although a previous review article described a higher prevalence of EBVpositive DLBCL among East Asians (8.7\%-11.4\%) compared with 5\% in Western countries (8), the frequency of EBV-positive DLBCL among DLCBL varies even in the same country among various reports. One of the reasons would be that the criteria for diagnosing EBV-positive DLBCL and the threshold for EBER differ in each report.

The percentage of EBV-positive DLBCL in DLBCL varies by the reports and regions as follows (the threshold for EBER positivity, regions): 11.4\% (not defined, Japan) (18), 5.7\% (counted by each step: $5-10 \%, 10-20 \%, 20-50 \%$, >50\%, Japan) (19), $4.5 \%$ ( $\geq 10 \%$, Taiwan) (20), $14.0 \%(\geq 20 \%$, Peru) (21), $5.3 \%$ (not defined, Turkey) (22), $2.5 \%$ ( $\geq 50 \%$, Europe) (23), $4.0 \%$ ( $\geq 20 \%$, Western Countries) (24).

\section{DIFFERENTIAL DIAGNOSIS}

The differential diagnosis of EBV-positive DLBCL is summarized in Table 1. Here, we describe the characteristics of each disease that should be distinguished from EBV-positive DLBCL in detail. 


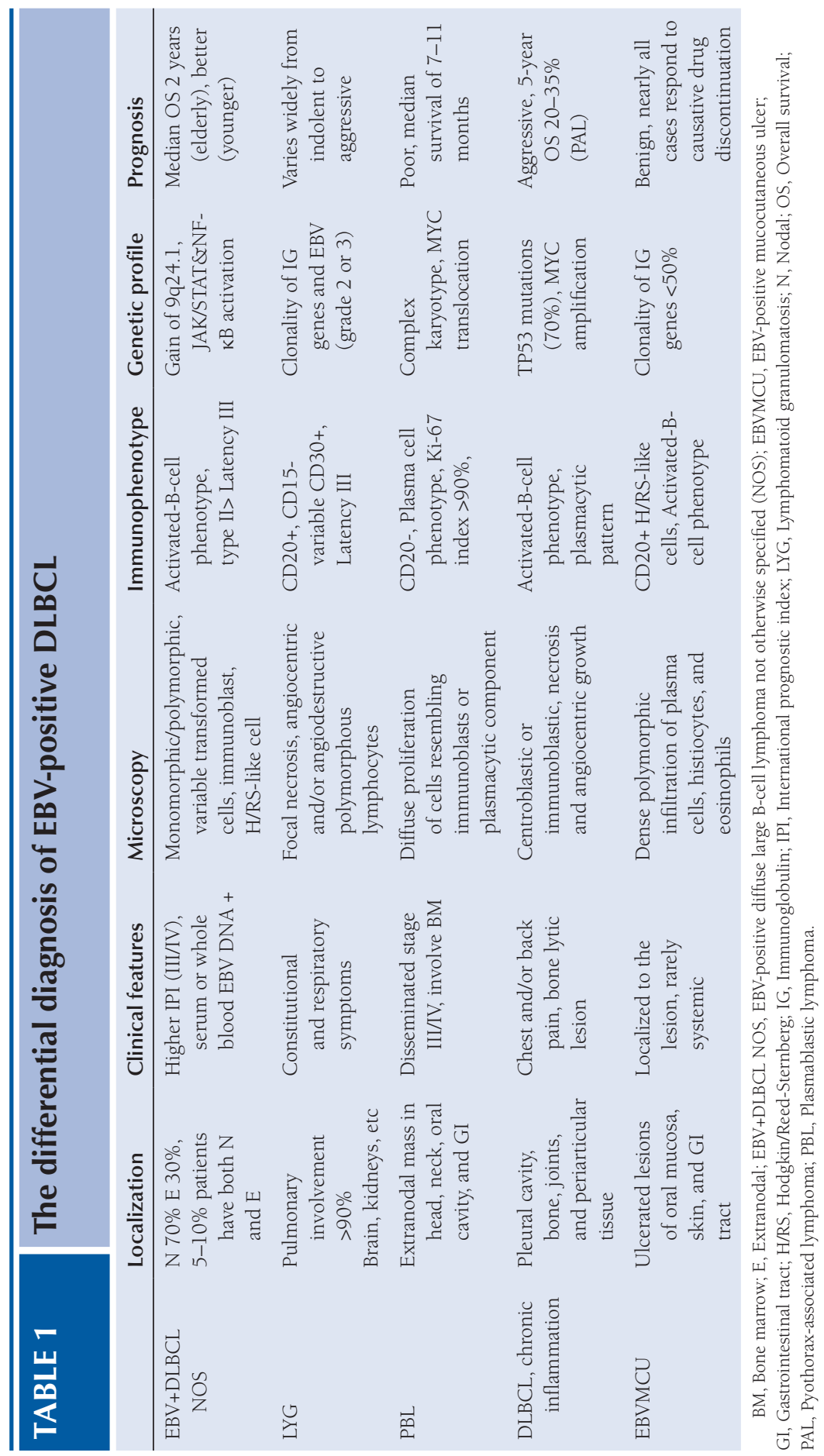




\section{Lymphomatoid granulomatosis}

Lymphomatoid granulomatosis (LYG) is a rare angiocentric and angiodestructive lymphoproliferative disease (25). The localization is predominantly extranodal, and pulmonary involvement occurs in $>90 \%$ of patients. Bone marrow involvement is extremely rare (26). Constitutional symptoms and respiratory symptoms are common, although patients with CNS involvement might be asymptomatic. Abundant polymorphous lymphocytes are infiltrated angiocentrically, admixed with plasma cells, immunoblasts, and histiocytes. LYG sometimes accompanies varying coagulative necrosis, especially in higher grade of the disease (27). Many small lymphocytes background are reactive $\mathrm{T}$ lymphocytes which show some atypia or irregularity $(25,26)$. Usually, a small number of large EBV-positive B-cells are found, reminiscent of Hodgkin/Reed-Sternberg cells.

The neoplastic cells are originated from B lymphocytes which are positive for EBV. The latency form is mainly Latency III because EBNA2 is positive with immunohistochemical staining (27). LMP1, which is universally positive with latency II, may be positive in larger atypical cells. EBV-positive B-cells are always positive for CD20 and variably positive for CD30, but negative for CD15. LYG is classified to 3 grades, based on the pathological findings. Clonality of IG genes and EBV are found in grade 2 or higher (25). The prognosis is varied widely to the grading. The progression-free survival (PFS) is 56\% (median follow-up of 5.1 years) in patients with LYG grade 1-2, and 44\% (median follow-up of 32 months) in patients with LYG grade 3 (27).

\section{Plasmablastic lymphoma}

Plasmablastic lymphoma (PBL) is a very aggressive lymphoma frequently seen in head, neck, and oral cavity (28). PBL occurs predominantly in adults with immunodeficiency, most commonly due to HIV infection. Other iatrogenic immunosuppression, including transplantation is a possible risk factor of PBL. Extranodal disseminated Stage III/IV disease is found in 75\% of HIV-positive patients (28). PBL shows variable morphological features from a diffuse and cohesive proliferation to cells with more obvious plasmacytic differentiation, and it resembles plasma cell myeloma. In these cases, a history of immune deficiency and the presence of EBV by in situ hybridization for EBER are useful to establish the diagnosis of PBL.

EBER is positive in $60-75 \%$ of cases, but LMP1 is rarely expressed, indicating type 1 latency of EBV $(28,29)$. The neoplastic cells express a plasma cell phenotype: positive for CD138, CD38, and IRF4/MUM1 with negativity for CD20. The Ki-67 proliferation index is usually very high (>90\%), which explains the aggressiveness of PBL. Complex karyotypes are frequently shown by genetic studies. MYC translocation has been identified in half of cases (30). The estimated median survival is $7-11$ months (31).

\section{Diffuse large B-cell lymphoma associated with chronic inflammation}

Diffuse large B cell lymphoma associated with chronic inflammation (DLBCL, chronic inflammation) is a lymphoid neoplasm which occurs when longstanding inflammation exists. Most cases involve body cavities such as pleural cavity or 
narrow spaces (32). Pyothorax-associated lymphoma (PAL), most of which have been reported in Japan, is a prototypical form. The causative factor of PAL is artificial pneumothorax for treatment of tuberculosis (33). PAL is strongly associated with EBV with expression of EBER, LMP1, and EBNA2 (usually Latency III). The probable cause of PAL is localized and confined inflammation with upregulated interleukin-10, by escaping from host immune surveillance (34).

The morphological features are similar to DLBCL, NOS. Most cases express CD20 and CD79a, otherwise some proportion of cases may show plasmacytic differentiation. The lymphoma has an activated B-cell phenotype, and CD30 can be expressed (32). TP53 mutations are frequently found ( 70\%), and MYC gene amplification is common (35). Downregulation of HLA class I expression might contribute to escaping of PAL cells from host cytotoxic T lymphocytes (36). The clinical course is aggressive and dismal, and the 5-year overall survival (OS) rate is $20-35 \%(32)$.

\section{EBV-positive mucocutaneous ulcer}

EBV-positive mucocutaneous ulcer (EBV-MCU) occurs in patients with age-related or iatrogenic immunosuppression (37). The localization is predominantly oral cavity, otherwise skin or gastrointestinal tract are involved. In almost half of patients, EBV-MCU regresses spontaneously without any treatment (38). Various immunosuppressive drugs (methotrexate, azathioprine cyclosporine, or tumor necrosis factor inhibitors) are considered as potential risk factors of EBV-MCU. Iatrogenically immunosuppressed EBV-MCU patients are younger on average than age-related EBV-MCU patients. EBV-MCU demonstrates ulcerated lesions, usually in oral mucosa, but shows no evidence of systemic lymphadenopathy, hepatosplenomegaly, or bone marrow involvement. The ulcer is sharply circumscribed, isolated, and indurated (37).

Beneath the ulcer, a dense polymorphic infiltrate with variable number of plasma cells, histiocytes, and eosinophils are scattered. A substantial number of large, transformed cells resemble either atypical immunoblasts or Hodgkin/ReedSternberg cells (38). Angioinvasion and necrosis can be present $(38,39)$. The large transformed immunoblasts and Hodgkin/Reed-Sternberg-like cells are variably positive for CD20. These cells show activated-B-cell phenotype and are CD30-positive. EBV is consistently positive for LMP1, with transformed cells commonly positive for EBER (37). Clonal IG gene rearrangements are proven in fewer than $50 \%$ of cases. The clinical course is rather benign compared to other EBV-related disorders. Spontaneous regression is possible, responding to reduction or discontinuation of immunosuppressive therapies.

\section{PATHOGENESIS}

EBV-positive DLBCL was formerly designated as EBV-positive DLBCL "of the elderly" because the disease was considered as an elderly-specific disease in the past. The relatively high frequency of EBV-positive DLBCL in the elderly is probably related to immunosenescence $(8,17)$. By aging process, an imbalance between inflammatory and anti-inflammatory networks arises, which results in 
low grade chronic pro-inflammatory status (40). Aging is associated with a progressive decline of both $\mathrm{B}$ and $\mathrm{T}$ lymphocytes with consequent losses in repertoire diversity (41). The losses of repertoire diversity alter the expression of costimulatory receptors, which increase the production of inflammatory cytokines. This imbalance and the losses of repertoire diversity are estimated as the background for promoting lymphomagenesis.

However, the hypothesis of age-related immuno senescence cannot fully explain the fact that EBV-positive DLBCL can also arise in young patients (42). Alterations in the immune microenvironment may play a crucial role for EBVpositive DLBCL regardless of age $(43,44)$. Ineffective T-cell immune response and abnormal tolerogenic immune environment are possible cause of EBV-positive DLBCL.

EBV is a family of gamma herpesvirus that primarily infects human epithelial cells and B lymphocytes, which establish a lifelong persistent and asymptomatic infection in memory B-cells. EBV life cycle can switch between latent and lytic states back and forward. The reactivation from latency and virus production is generated by environmental stimuli but usually is controlled tightly by the immune system (45). Most viral particles are cleared by host cytotoxic T cells. However, EBV survives by establishing latency as an episome (a double-stranded circular form of the genome) in memory B-cells (8).

The "latency" status of EBV in vivo is distinguished to 3 patterns named Latency I, II, and III. Various EBV-gene expression is seen in Latency I, II, and III. The latency III, which is observed in 7-28\% of EBV-positive DLBCL $(17,44)$, is characterized by the expression of all 6 EBV nuclear antigens (EBNA1, 2, 3A, 3B, 3C, and LP), 3 latent membrane proteins (LMP1, 2A, and 2B), and EBER. Latency III pattern is similar to posttransplantation lymphoproliferative disease. Latency II is defined by the expression of EBNA1, LMP1, LMP2A, and EBER and is seen in most of the EBV-positive DLBCL and classical Hodgkin lymphoma. The representative disease of Latency I is Burkitt lymphoma, characterized by EBNAI and EBER expression (8).

DLBCL is subdivided into two groups by cell of origin, i.e., GCB and ABC subtypes. The classification is defined according to the gene expression profiling and is useful to predict the prognosis (46). Most of EBV-positive DLBCL show ABC

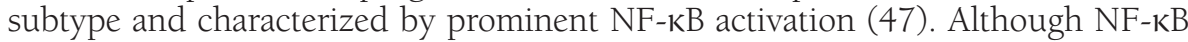
activation is usually observed in ABC subtype of DLBCL, constant activation is seen in EBV-positive DLBCL regardless of cell of origin. EBV can elicit NF-kB responses by mimicking B-cell receptor and CD40 signaling cascades through the encoded proteins LMP2A (48) and LMP1 (49). These findings seem to be related to c-Rel (a subunit of NF-kB transcription factor) amplification, which has been observed exclusively in the GCB immunophenotype of DLBCL (8).

LMP1 has a crucial role in the oncogenic process of EBV $(8,44,50,51)$. LMP1 is an integral membrane protein consisting of 3 different domains. The N-terminal cytoplasmic domain specifies LMP1 protein and binds to the plasma membrane. On the contrary, the long C-terminal cytoplasmic tail defines signal transduction. Between the C- and N-terminal domains, a platform for self-aggregation and oligomerization exists (8). LMP1 functionally mimics CD40, which is expressed constitutively on the B-cell membrane and involved in B-cell activation and proliferation. Interestingly, the function of LMP1 is ligand-independent and is constitutively activated as a result of self-aggregation and oligomerization (52). 
The aggregation of LMP1 molecules in the plasma membrane recruit tumor necrosis factor receptor-associated factors (TRAFs) which are presumably leading to NF-kB activation. In this process, phosphatidyl-inositol 3-kinase (PI3K) and Akt, a downstream target of PI3K, are also activated by LMP1 (53). A 30-bp deleting mutation located in the C-terminal domain of LMP1, which is frequently seen in EBV-related lymphoproliferative diseases, is reported to prolong the half-life of LMP-1, resulting in a higher level of LMP1 expression (54). Although the existence of LMP1 is not sufficient for B-cell immortalization by EBV, LMP1 has a key role for the tumorigenesis by NF-kB activation.

Clonality of immunoglobulin gene and EBV can be detected by molecular technique, which is useful to distinguish EBV-positive DLBCL from reactive hyperplasia and infectious mononucleosis $(17,44)$. The gene expression profiling suggests that the host immune response is a key molecular signature in EBVpositive DLBCL (55). Copy number alterations of EBV-positive DLBCL were thoroughly investigated, which revealed that antiviral response genes, proinflammatory cytokines, and chemokines associated with the innate immune response were overexpressed.

The upregulation of PDL2 on 9q24.1 suggests the promoting of immune evasion. Utilizing high-throughput sequencing, PD-L1/PD-L2-involving genetic aberrations were observed in 19\% of EBV-positive DLBCL (56). In addition, EBVpositive DLBCL exhibits distinct genetic profiles from EBV-negative DLBCL. EBVpositive DLBCL is characterized by frequent TET2 and DNMT3A mutations with the paucity of CDKN2A and FAS alterations. JAK/STAT and NF-kB signaling are activated in EBV-positive DLBCL, but the mutation of chromatin remodeling genes, including EZH2, CD79B, CARD11, and MYD88 are few or not found (56-58). Further investigations of genetic signature would be helpful to elucidate the etiology of EBV-positive DLBCL.

\section{PATHOLOGICAL FINDINGS}

DLBCL is a common neoplasm in which atypical lymphocytes are more than twice the size of normal lymphocytes, or at least larger than normal macrophages. Centroblastic variant is the most common, and otherwise immunoblastic variant or mixed type are seen. The tumorous cells are proliferated diffusely, which is why it is named as "diffuse" large B-cell lymphoma. If morphological, biological, and clinical features are prominent, the diagnosis should be made as other disease entities, including EBV-positive DLBCL. The presence of EBV-positive cells should lead to a diagnosed EBV-positive DLBCL rather than DLBCL, NOS.

The pathological feature of EBV-positive DLBCL is similar to other EBV-related neoplasms such as EBV-positive classic Hodgkin lymphoma. The atypical lymphocytes are middle to large sized and proliferated nodular or vaguely nodular, while the others are proliferated diffusely. EBV-positive DLBCL is classified into two distinct patterns: polymorphic and monomorphic. Polymorphic pattern characterized with abundant reactive components including small lymphocytes, plasma cells, and histiocytes is dominant subtype (Figure 2A and 2B), while monomorphic subtype is seen in 2-23\% of EBV-positive DLBCL $(8,14,47,59)$. In both subtypes, variable number of large, transformed cells, immunoblasts, and 

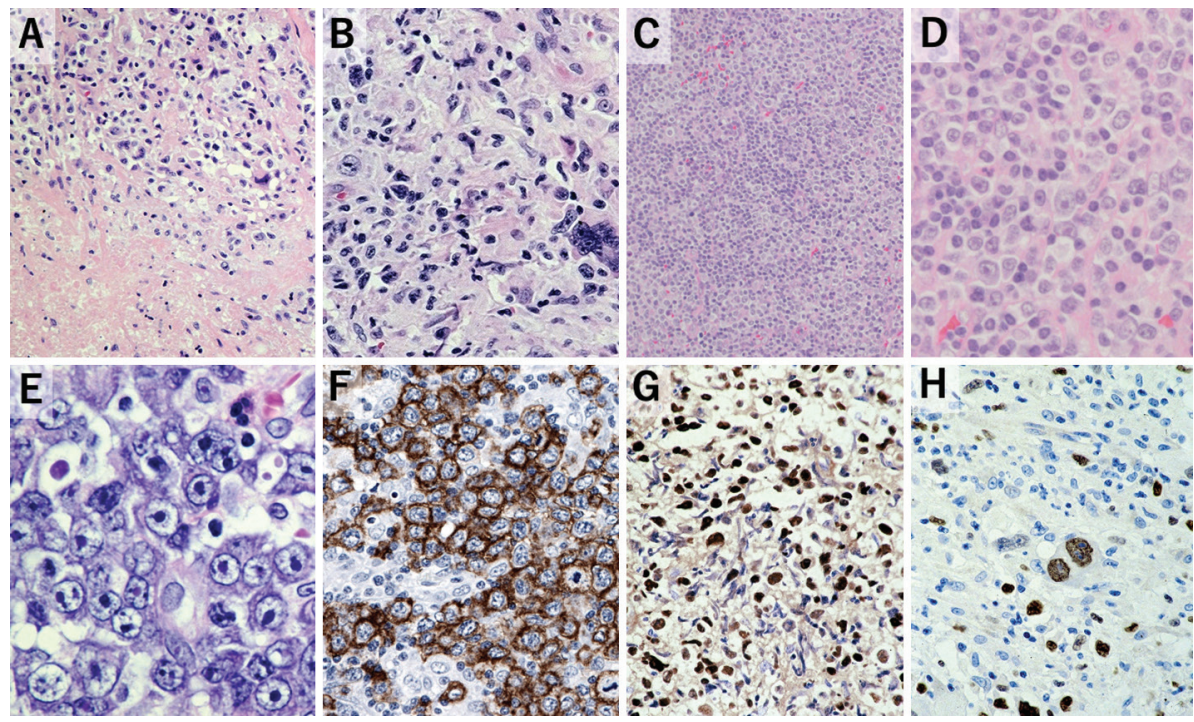

Figure 2. Pathological findings. Polymorphous subtype: Geographical necrosis with medium to large sized atypical lymphocytes (A, HE x100). Atypical lymphocytes exhibit polymorphous pattern accompanied with giant cell (B, HE x400). Polymorphous subtype/T-cell/histocyte-rich B-cell lymphoma-like: Atypical large lymphocytes are scattered with background small lymphocyte without geographical necrosis (C, HE x100 and D, HE x400). Large cell lymphoma subtype: Atypical large lymphocytes are diffusely proliferated (E, HE x400). The atypical lymphocytes are positive for CD20 (F, $x 400)$. The nuclear of atypical lymphocytes are positive for both EBER1 in situ hybridization $(\mathbf{G})$ and EBNA2 $(\mathbf{H})$ (x200, respectively). EBER, EBVencoded RNA; EBNA; Epstein-Barr nuclear antigens; HE, Hematoxylin-Eosin Stain.

Hodgkin/Reed-Sternberg like cells are scattered. The abundant background of small lymphocytes frequently resembles T-cell/histiocyte-rich large B-cell lymphoma (Figure 2C and 2D) and is the most common pattern among patients under 45 years of age (44). Geographical necrosis is found in about one-third of EBV-positive DLBCL, although this is not specific (59). Geographical necrosis is also seen in other EBV-related diseases, including LYG and EBV-MCU. If pathological findings show monomorphic pattern, differential diagnosis is difficult without ancillary studies (14).

Montes-Moreno et al. described 47 cases of EBV-positive DLBCL and investigated the pathological features (47). In their study, 46 cases were polymorphic and only 1 case was monomorphic. They subdivided the polymorphous EBVpositive DLBCL into 3 categories: Large B-cell-type (29 cases, 62\%); Polymorphic LPD-type (9 cases, 19\%); and Hodgkin-like type (8 cases, 17\%). Large B-cell-type is characterized with high density of large neoplastic cells (Figure 2E) and scattered cells with Reed-Sternberg-like and Hodgkin-like features. Polymorphic LPD-type have low density of neoplastic cells without Hodgkin lymphoma-like features. Hodgkin-like type has lower density of neoplastic cells with ReedSternberg-like and Hodgkin-like features. One case of monomorphic pattern was composed of a neoplastic pure immunoblastic large-cell population. Although the classification is useful to grasp the pathological overview, these polymorphic variants do not have an impact on prognostic significance $(8,14)$. 
The neoplastic cells are positive for pan-B-cell antigens including CD19, CD20 (Figure 1F), CD22, CD79a, and PAX5. Moreover, 63-100\% of EBV-positive DLBCL show the ABC/non-GCB phenotype, being positive for IRF/MUMl and negative for CD10 and BCL6 $(14,42,59,60)$. This is in contrast to the fact that the $\mathrm{ABC} /$ non-GCB subtype is less dominant among DLBCL, NOS overall (61). A previous study revealed that in 50-60 years of age, the ABC/non-GCB subtype consists $33 \%$ of DLBCL, while $54 \%$ of DLBCL was the ABC/non-GCB subtype if the age was over 80 years (62). They observed an average increase of $7.5-13.7 \%$ in $\mathrm{ABC} /$ non-GCB subtype DLBCL for each ten years of aging after the age of 50 years. The $\mathrm{ABC} /$ non-GCB subtype increases with age possibly due to accumulation of genomic abnormality (63), parallel to the increase of EBV-positive DLBCL among the elderly. CD30 is frequently positive, and CD15 is sometimes expressed in EBV-positive DLBCL (14). This immunohistochemical feature is similar to that of classic Hodgkin lymphoma. However, other phenotypic features of classic Hodgkin lymphoma are lacking. The pan-B-cell antigens are strongly positive in EBV-positive DLBCL, and more frequently contain necrotic lesion than classic Hodgkin lymphoma (64).

In situ hybridization for EBER is mandatory to diagnose EBV-positive DLBCL (14). More than $80 \%$ of atypical lymphocytes are positive for EBER staining (Figure $1 \mathrm{G}$ ). LMP1 and EBNA2 (Figure $1 \mathrm{H}$ ) are expressed in $>90 \%$ and $7-28 \%$, respectively, indicating Latency II and III $(17,44)$. PDL1 and PDL2 are frequently positive for the tumor cells, which suggests the mechanism for immune escape (43). In 4-5\% cases of EBV-positive DLBCL, EBV is not only positive for the tumor cells, but also seen in non-neoplastic bystander B cells, providing the result of local immune escape (65). Both EBV DNA load and EBER status in diagnostic specimen are prognostic factors. Among the patients of DLBCL, NOS, EBV DNA load above 700 copies/ $\mu$ is an independent poor prognostic factor for PFS and OS (66). In addition, EBER-positive patients have significantly worse outcomes than negative patients, although a conflicting result is reported (67).

The prognosis of EBV-positive DLBCL in the elderly is dismal, and the estimated median OS is about 2 years (14). Only $21 \%$ of patients could survive longer than 2 years in a case series (68). On the contrary, younger patients have better prognosis, with long term complete remission rate of $>80 \%(44,69)$. The T-cell/histiocyte-rich large B-cell subtype, which is a dominant subtype in younger patients, confers a better prognosis than monomorphic EBV-positive DLBCL. CD30 is commonly (42.9\%) positive for EBV-positive DLBCL and is a poor prognostic factor (24). On the other hand, CD30 positivity which is observed in $\sim 14 \%$ of DLBCL, NOS is considered as a favorable prognostic factor (70). EBNA2 positivity also has a poor prognosis in European cohort (23). Unfortunately, a standardized EBER positivity cut off value does not exist to date to diagnose EBV-positive DLBCL. Because of the variation of EBER positivity cut-off criteria in each study, simple comparison among studies is difficult (19).

\section{CLINICAL FEATURES}

According to the study by Oyama et al. (17), the patient characteristics of EBVpositive LPDs mainly consisting of DLBCL (EBV-positive DLBCL group) showed 
Eastern Cooperative Oncology Group performance status (ECOG PS) of 2-4 (44\%), the presence of B symptom (49\%), high serum lactate dehydrogenase (LDH) level (58\%), Ann Arbor stage III-IV (58\%), and extranodal involvement >1 site (33\%). Patients with high intermediate and high IPI was 54\%. Compared to the EBV-negative DLBCL group including 107 patients aged over 40 years with EBV-negative DLBCL, the characteristics of higher frequency were as follows: ECOG PS 2-4 ( $<<0.0001)$, the presence of B symptoms (49\%, P < 0.0001), and high intermediate and high IPI $(\mathrm{P}=0.0017)$. The total incidence of extranodal involvement was similar between the EBV-positive DLBCL group and the EBVnegative DLBCL group (69\% and 72\%, respectively). Among the EBV-positive DLBCL group, $31 \%$ had only lymphadenopathy without extranodal involvement, 49\% had lymphadenopathy with extranodal involvement, and 20\% had a disease limited to extranodal sites. The main sites of extranodal involvement in the EBVpositive DLBCL group were skin (13\%), lung (9\%), pleural effusion (9\%), stomach (9\%), and tonsil (8\%). A comparison between EBV-positive and EBV-negative groups showed that the incidence of cutaneous involvement was significantly higher in the EBV-positive DLBCL group than that of the EBV-negative DLBCL group $(\mathrm{P}=0.027)(17)$.

Analyses on serum EBV antibody titers among the EBV-positive DLBCL group have been reported. An abnormal anti-EBV antibody titer was defined when anti-EBV VCA IgG antibody was 640 -fold or higher, or anti-EBNA antibody was negative.

Among EBV-positive DLBCL group, 67\% had an abnormal anti-EBV antibody titer. On the other hand, among EBV-negative DLBCL group, only $24 \%$ had an abnormal anti-EBV antibody titer. The percentage of patients with abnormal serum EBV antibody titers was significantly higher in the EBV-positive DLBCL group compared to the EBV-negative DLBCL group (17).

According to the research by Tokuyama et al., computed tomography (CT) findings in EBV-positive DLBCL are characterized by the higher frequency of the presence of nodal and extranodal necrosis compared with EBV-negative DLBCL (diagnosis criteria of necrosis for CT were defined as focal or diffuse areas of nonenhancing parenchyma depicted during an examination with bolus administration of contrast material). Nodal and extranodal necrosis was found in $66.7 \%$ of EBV-positive DLBCL and in 15.4\% of 39 patients with EBV-negative DLBCL (71).

The detection of EBV DNA load and EBER status have been reported. Among 140 DLBCL patients, 51 patients were evaluable for both EBER (the threshold for EBER positivity 220) and EBV DNA load, 83 patients for EBER only, and one for EBV DNA load only. The median EBV DNA load was 708 copies/ug. EBV DNA load was significantly higher for EBER-positive patients than for EBER-negative patients. Moreover, EBV DNA was detected in up to $72 \%$ of EBER-negative patients (66).

\section{TREATMENT AND OUTCOME}

The standard therapy for DLBCL is R-CHOP therapy (3). R-CHOP therapy is an effective and well-tolerated treatment. The frequent adverse events by R-CHOP therapy (Grade 3-4, according to the National Cancer Institute Common Toxicity 
Criteria: CTCAE version 2.0.) include infection (12\%), cardiac toxicity (8\%), lung toxicity ( $8 \%$ ), neurologic toxicity (5\%), nausea or vomiting (4\%), mucositis (3\%), liver toxicity (3\%), fever (2\%), constipation (2\%), and renal toxicity (1\%) (72). Infections with neutropenia can be severe and should be given the most attention.

The optimal cycles of R-CHOP or dose of radiation therapy should be modified depending on the stage and the presence of bulky mass. The definition of bulky mass varies in each clinical trial $(7.5 \mathrm{~cm}$ or $10 \mathrm{~cm}$ in diameter) $(73,74)$. The treatment strategy of DLBCL is roughly divided into two types: for patients with Ann Arbor stage I-II without bulky mass, and for those with stage III-IV or with and without bulky mass.

Regarding the treatment of patients with Ann Arbor stage I-II within the observation period of 5 years, among patients with stage I including patients with bulky mass (defined $\geq 10 \mathrm{~cm}$ in diameter) and stage II without bulky mass, three courses of CHOP plus involved-field radiotherapy improved PFS, and OS were compared to those of eight cycles of $\mathrm{CHOP}$ without radiotherapy (73). Based on these results, three courses of R-CHOP therapy plus involved-field radiotherapy is regarded as the standard therapy for this patient group. However, when the observation period is extended beyond five years, there was no difference in PFS and OS between the two groups (75). Furthermore, for patients with a better prognosis, as described below, four courses of R-CHOP can be a treatment option. Namely, patients aged 18-60 years, stage I-II disease, normal serum LDH, ECOG performance status $0-1$, and without bulky mass (diameter $<7.5 \mathrm{~cm}$ ) have a better prognosis. In these patients, there is no difference in treatment outcomes between four and six cycles of R-CHOP therapy. After 4 cycles of R-CHOP in these patients, 3-year event-free survival was 89\%, and 3-year OS was 99\% (74).

Regarding the treatment of patients with Ann arbor stage I-II with or without bulky mass, the 8 courses of R-CHOP therapy did not improve the outcome compared to the 6 courses of R-CHOP therapy. Therefore, 6 cycles of R-CHOP are considered to be standard therapy $(76,77)$. Treatment outcomes in elderly patients have also been reported. The outcomes of 8 cycles R-CHOP therapy in patients aged 60-80 years with DLBCL have been reported. This study included patients with stage II-IV, performance status $0-2$, and did not include patients with CNS invasion. Response rates were $75 \%$ for complete response and undocumented complete response, $8 \%$ and $6 \%$ for incomplete responses (partial response and stable disease), $9 \%$ for progressive disease, and $6 \%$ for death during treatment. The 5-year disease free survival and OS were 66\% and 58\%, respectively (78).

\section{Treatment outcome of EBV-positive DLBCL}

EBV-positive DLBCL is also usually treated with R-CHOP (8). Response to frontline treatment (complete remission or partial remission) of EBV-positive (the threshold for EBER positivity 220 ) patients and EBV-negative patients was $72 \%$ and $92.3 \%$, respectively $(\mathrm{P}=0.006)$. Thus, EBV-positive DLBCL patients have a significantly lower response rate to first-line therapy (50). After a median followup duration of 40.5 months (range, 1-165.7 months), the 5-year OS and PFS rates of EBV-positive DLBCL patients were $58.9 \%$ and $48.6 \%$, respectively (50). The EBV-positive DLBCL patients showed poorer OS compared to EBV-negative 
patients (35.8 months vs not reached, $\mathrm{P}=0.026$ ). Similarly, the EBV-positive DLBCL patients showed poorer PFS (12.8 months vs 35.8 months, $\mathrm{P}=0.018$ ) compared to EBV-negative patients (50). In the future, there are possible therapeutic approaches as follows; EBV-specific adoptive immunotherapy, microRNAtargeted therapy, monoclonal antibodies including Brentuximab Vedotin, and targeting specific signaling pathways, including the $\mathrm{NF}-\mathrm{kB}$ pathway $(8,79)$.

\section{CONCLUSION}

EBV-positive DLBCL has distinctive pathological and clinical features among DLBCL subtypes. It is usually treated with R-CHOP therapy, but the survival period is shorter than that of EBV-negative DLBCL. Therefore, diagnosis of EBVpositive DLBCL by pathological evaluation contributes to prognostic predictions. More streamlined treatment strategy and novel therapeutics are needed for this unique subtype of DLBCL.

Acknowledgement: We appreciate Dr. Koichi Ohshima for providing the pathology images.

Conflict of Interest: TT reports personal fees from Medical Network Systems Inc., and Bionics co., ltd, outside the submitted work. Other authors have no conflicts of interest.

Copyright and Permission Statement: The authors confirm that the materials included in this chapter do not violate copyright laws. Where relevant, appropriate permissions have been obtained from the original copyright holder(s), and all original sources have been appropriately acknowledged or referenced.

\section{REFERENCES}

1. Gascoyne RD, Campo E, Jaffe ES, Chan WC, Chan JKC, Rosenwald A, et al. Diffuse large B-cell lymphoma, NOS. In: Swerdlow SH, Campo E, Harris NL, Jaffe ES, Pileri SA, Stein H, et al. editors. WHO Classification of Tumours of Haematopoietic and Lymphoid Tissues. Revised 4th Edition ed. Lyon: International Agency for Research on Cancer; 2017. p. 291-7.

2. Thandra KC, Barsouk A, Saginala K, Padala SA, Barsouk A, Rawla P. Epidemiology of Non-Hodgkin's Lymphoma. Med Sci (Basel). 2021;9(1). https://doi.org/10.3390/medsci9010005

3. Sehn LH, Salles G. Diffuse Large B-Cell Lymphoma. N Engl J Med. 2021;384(9):842-58. https://doi. org/10.1056/NEJMra2027612

4. A Clinical Evaluation of the International Lymphoma Study Group Classification of Non-Hodgkin's Lymphoma. Blood. 1997;89(11):3909-18. https://doi.org/10.1182/blood.V89.11.3909

5. Cheson BD, Fisher RI, Barrington SF, Cavalli F, Schwartz LH, Zucca E, et al. Recommendations for initial evaluation, staging, and response assessment of Hodgkin and non-Hodgkin lymphoma: the Lugano classification. J Clin Oncol. 2014;32(27):3059-68. https://doi.org/10.1200/JCO.2013.54.8800

6. Ruppert AS, Dixon JG, Salles G, Wall A, Cunningham D, Poeschel V, et al. International prognostic indices in diffuse large B-cell lymphoma: a comparison of IPI, R-IPI, and NCCN-IPI. Blood. 2020;135(23):2041-8. https://doi.org/10.1182/blood.2019002729 
7. Scott DW, Anja M, Daisuke E, Wright GW, Pedro F, Ben-Neriah S, et al. Prognostic Significance of Diffuse Large B-Cell Lymphoma Cell of Origin Determined by Digital Gene Expression in FormalinFixed Paraffin-Embedded Tissue Biopsies. J Clin Oncol. 2015;33(26):2848-56. https://doi. org/10.1200/JCO.2014.60.2383

8. Ok CY, Papathomas TG, Medeiros LJ, Young KH. EBV-positive diffuse large B-cell lymphoma of the elderly. Blood. 2013;122(3):328-40. https://doi.org/10.1182/blood-2013-03-489708

9. Nowalk A, Green M. Epstein-Barr Virus. Microbiol Spectr. 2016;4(3). https://doi.org/10.1128/microbiolspec.DMIH2-0011-2015

10. Cohen JI. Epstein-Barr Virus Infection. N Engl J Med. 2000;343(7):481-92. https://doi.org/10.1056/ NEJM200008173430707

11. Young LS, Rickinson AB. Epstein-Barr virus: 40 years on. Nat Rev Cancer. 2004;4(10):757-68. https://doi.org/10.1038/nrcl452

12. Young LS, Yap LF, Murray PG. Epstein-Barr virus: more than 50 years old and still providing surprises. Nat Rev Cancer. 2016;16(12):789-802. https://doi.org/10.1038/nrc.2016.92

13. Healy JA, Dave SS. The Role of EBV in the Pathogenesis of Diffuse Large B Cell Lymphoma. Curr Top Microbiol Immunol. 2015;390(Pt 1):315-37. https://doi.org/10.1007/978-3-319-22822-8_13

14. Nakamura S, Jaffe ES, Swerdlow SH. EBV-positive diffuse large B-cell lymphoma, not otherwise specified (NOS). In: Swerdlow SH, Campo E, Harris NL, Jaffe ES, Pileri SA, Stein H, et al. editors. WHO Classification of Tumours of Haematopoietic and Lymphoid Tissues. Revised 4th Edition ed. Lyon: International Agency for Research on Cancer; 2017. p. 304-6.

15. Cerhan JR, Kricker A, Paltiel O, Flowers CR, Wang SS, Monnereau A, et al. Medical history, lifestyle, family history, and occupational risk factors for diffuse large B-cell lymphoma: the InterLymph NonHodgkin Lymphoma Subtypes Project. J Natl Cancer Inst Monogr. 2014;2014(48):15-25. https://doi. org/10.1093/jncimonographs/gu010

16. Oksenhendler E, Boulanger E, Galicier L, Du M-Q, Dupin N, Diss TC, et al. High incidence of Kaposi sarcoma-associated herpesvirus-related non-Hodgkin lymphoma in patients with HIV infection and multicentric Castleman disease. Blood. 2002;99(7):2331-6. https://doi.org/10.1182/blood. V99.7.2331

17. Oyama T, Yamamoto K, Asano N, Oshiro A, Suzuki R, Kagami Y, et al. Age-related EBV-associated B-cell lymphoproliferative disorders constitute a distinct clinicopathologic group: a study of 96 patients. Clin Cancer Res. 2007;13(17):5124-32. https://doi.org/10.1158/1078-0432.CCR-06-2823

18. Kuze T, Nakamura N, Hashimoto Y, Sasaki Y, Abe M. The characteristics of Epstein-Barr virus (EBV)positive diffuse large B-cell lymphoma: comparison between EBV(+) and EBV(-) cases in Japanese population. Jpn J Cancer Res. 2000;91(12):1233-40. https://doi.org/10.1111/j.1349-7006.2000.tb00909.x

19. Wada N, Ikeda J, Hori Y, Fujita S, Ogawa H, Soma T, et al. Epstein-barr virus in diffuse large B-Cell lymphoma in immunocompetent patients in Japan is as low as in Western Countries. J Med Virol. 2011;83(2):317-21. https://doi.org/10.1002/jmv.21967

20. Chang ST, Lu YH, Lu CL, Weng SF, Lin SH, Kuo SY, et al. Epstein-Barr virus is rarely associated with diffuse large B cell lymphoma in Taiwan and carries a trend for a shorter median survival time. J Clin Pathol. 2014;67(4):326-32. https://doi.org/10.1136/jclinpath-2013-201905

21. Beltran BE, Castillo JJ, Morales D, De Mendoza FH, Quinones P, Miranda RN, et al. EBV-positive diffuse large B-cell lymphoma of the elderly: A case series from Peru. Am J Hematol. 2011;86(8):663-7. https://doi.org/10.1002/ajh.22078

22. Uner A, Akyurek N, Saglam A, Abdullazade S, Uzum N, Onder S, et al. The presence of Epstein-Barr virus (EBV) in diffuse large B-cell lymphomas (DLBCLs) in Turkey: special emphasis on 'EBV-positive DLBCL of the elderly'. Apmis. 2011;119(4-5):309-16. https://doi.org/10.1111/j.1600-0463.2011.02736.x

23. Stuhlmann-Laeisz C, Borchert A, Quintanilla-Martinez L, Hoeller S, Tzankov A, Oschlies I, et al. In Europe expression of EBNA2 is associated with poor survival in EBV-positive diffuse large B-cell lymphoma of the elderly. Leuk Lymphoma. 2016;57(1):39-44. https://doi.org/10.3109/10428194.2015. 1040014

24. Ok CY, Li L, Xu-Monette ZY, Visco C, Tzankov A, Manyam GC, et al. Prevalence and Clinical Implications of Epstein-Barr Virus Infection in De Novo Diffuse Large B-Cell Lymphoma in Western Countries. Clin Cancer Res. 2014;20(9):2338-49. https://doi.org/10.1158/1078-0432.CCR-13-3157 
25. Pittaluga S, Wilson WH, Jaffe ES. Lymphomatoid granulomatosis. In: Swerdlow SH, Campo E, Harris NL, Jaffe ES, Pileri SA, Stein H, et al., editors. WHO Classification of Tumours of Haematopoietic and Lymphoid Tissues. Revised 4th Edition ed. Lyon: International Agency for Research on Cancer; 2017. p. 312-4.

26. Melani C, Jaffe ES, Wilson WH. Pathobiology and treatment of lymphomatoid granulomatosis, a rare EBV-driven disorder. Blood. 2020;135(16):1344-52. https://doi.org/10.1182/blood.2019000933

27. Song JY, Pittaluga S, Dunleavy K, Grant N, White T, Jiang L, et al. Lymphomatoid Granulomatosis-A Single Institute Experience. Am J Surg Pathol. 2015;39(2):141-56. https://doi.org/10.1097/ PAS.0000000000000328

28. Campo E, Stein H, Harris NL. Plasmablastic lymphoma. In: Swerdlow SH, Campo E, Harris NL, Jaffe ES, Pileri SA, Stein H, et al., editors. WHO Classification of Tumours of Haematopoietic and Lymphoid Tissues. Revised 4th Edition ed. Lyon: International Agency for Research on Cancer; 2017. p. 321-2.

29. Liu F, Asano N, Tatematsu A, Oyama T, Kitamura K, Suzuki K, et al. Plasmablastic lymphoma of the elderly: a clinicopathological comparison with age-related Epstein-Barr virus-associated B cell lymphoproliferative disorder. Histopathology. 2012;61(6):1183-97. https://doi.org/10.1111/j.1365-2559.2012.04339.x

30. Valera A, Balagué O, Colomo L, Martínez A, Delabie J, Taddesse-Heath L, et al. IG/MYC rearrangements are the main cytogenetic alteration in plasmablastic lymphomas. Am J Surg Pathol. 2010;34(11):1686-94. https://doi.org/10.1097/PAS.0b013e3181f3e29f

31. Castillo JJ, Bibas M, Miranda RN. The biology and treatment of plasmablastic lymphoma. Blood. 2015;125(15):2323-30. https://doi.org/10.1182/blood-2014-10-567479

32. Chan JKC, Aozasa K, Gaulard P. Diffuse large B-cell lymphoma associated with chronic inflammation. In: Swerdlow SH, Campo E, Harris NL, Jaffe ES, Pileri SA, Stein H, et al., editors. WHO Classification of Tumours of Haematopoietic and Lymphoid Tissues. Revised 4th Edition ed. Lyon: International Agency for Research on Cancer; 2017. p. 309-11.

33. Nakatsuka S, Yao M, Hoshida Y, Yamamoto S, Iuchi K, Aozasa K. Pyothorax-associated lymphoma: a review of 106 cases. J Clinical Oncol. 2002;20(20):4255-60. https://doi.org/10.1200/ JCO.2002.09.021

34. Kanno H, Naka N, Yasunaga Y, Iuchi K, Yamauchi S, Hashimoto M, et al. Production of the immunosuppressive cytokine interleukin-10 by Epstein-Barr-virus-expressing pyothorax-associated lymphoma: possible role in the development of overt lymphoma in immunocompetent hosts. Am J Pathol. 1997;150(1):349-57.

35. Yamato H, Ohshima K, Suzumiya J, Kikuchi M. Evidence for local immunosuppression and demonstration of c-myc amplification in pyothorax-associated lymphoma. Histopathology. 2001;39(2): 163-71. https://doi.org/10.1046/j.1365-2559.2001.01197.x

36. Kanno H, Nakatsuka S, Iuchi K, Aozasa K. Sequences of cytotoxic T-lymphocyte epitopes in the Epstein-Barr virus (EBV) nuclear antigen-3B gene in a Japanese population with or without EBV-positive lymphoid malignancies. Int J Cancer. 2000;88(4):626-32. https://doi. org/10.1002/1097-0215(20001115)88:4<626::AID-IJC17>3.0.CO;2-Q

37. Gaulard P, Swerdlow SH, Harris NL, Sundström C, Jaffe ES. EBV-positive mucocutaneous ulcer. In: Swerdlow SH, Campo E, Harris NL, Jaffe ES, Pileri SA, Stein H, et al., editors. WHO Classification of Tumours of Haematopoietic and Lymphoid Tissues. Revised 4th Edition ed. Lyon: International Agency for Research on Cancer; 2017. p. 307-8.

38. Dojcinov SD, Venkataraman G, Raffeld M, Pittaluga S, Jaffe ES. EBV positive mucocutaneous ulcer--a study of 26 cases associated with various sources of immunosuppression. Am J Surg Pathol. 2010;34(3):405-17. https://doi.org/10.1097/PAS.0b013e3181cf8622

39. Dojcinov SD, Venkataraman G, Pittaluga S, Wlodarska I, Schrager JA, Raffeld M, et al. Age-related EBV-associated lymphoproliferative disorders in the Western population: a spectrum of reactive lymphoid hyperplasia and lymphoma. Blood. 2011;117(18):4726-35. https://doi.org/10.1182/ blood-2010-12-323238

40. Franceschi C, Capri M, Monti D, Giunta S, Olivieri F, Sevini F, et al. Inflammaging and anti-inflammaging: a systemic perspective on aging and longevity emerged from studies in humans. Mech Ageing Dev. 2007;128(1):92-105. https://doi.org/10.1016/j.mad.2006.11.016 
41. Hakim FT, Gress RE. Immunosenescence: deficits in adaptive immunity in the elderly. Tissue Antigens. 2007;70(3):179-89. https://doi.org/10.1111/j.1399-0039.2007.00891.x

42. Hong JY, Yoon DH, Suh C, Huh J, Do IG, Sohn I, et al. EBV-positive diffuse large B-cell lymphoma in young adults: is this a distinct disease entity? Ann Oncol. 2015;26(3):548-55. https://doi. org/10.1093/annonc/mdu556

43. Chen BJ, Chapuy B, Ouyang J, Sun HH, Roemer MG, Xu ML, et al. PD-Ll expression is characteristic of a subset of aggressive B-cell lymphomas and virus-associated malignancies. Clin Cancer Res. 2013;19(13):3462-73. https://doi.org/10.1158/1078-0432.CCR-13-0855

44. Nicolae A, Pittaluga S, Abdullah S, Steinberg SM, Pham TA, Davies-Hill T, et al. EBV-positive large B-cell lymphomas in young patients: a nodal lymphoma with evidence for a tolerogenic immune environment. Blood. 2015;126(7):863-72. https://doi.org/10.1182/blood-2015-02-630632

45. Kempkes B, Robertson ES. Epstein-Barr virus latency: current and future perspectives. Curr Opin Virol. 2015;14:138-44. https://doi.org/10.1016/j.coviro.2015.09.007

46. Rosenwald A, Staudt LM. Gene expression profiling of diffuse large B-cell lymphoma. Leuk Lymphoma. 2003;44 Suppl 3:S41-7. https://doi.org/10.1080/10428190310001623775

47. Montes-Moreno S, Odqvist L, Diaz-Perez JA, Lopez AB, de Villambrosía SG, Mazorra F, et al. EBVpositive diffuse large B-cell lymphoma of the elderly is an aggressive post-germinal center B-cell neoplasm characterized by prominent nuclear factor-kB activation. Mod Pathol. 2012;25(7):968-82. https://doi.org/10.1038/modpathol.2012.52

48. Mancao C, Hammerschmidt W. Epstein-Barr virus latent membrane protein 2A is a B-cell receptor mimic and essential for B-cell survival. Blood. 2007;110(10):3715 21. https://doi.org/10.1182/ blood-2007-05-090142

49. Mosialos G, Birkenbach M, Yalamanchili R, VanArsdale T, Ware C, Kieff E. The Epstein-Barr virus transforming protein LMPl engages signaling proteins for the tumor necrosis factor receptor family. Cell. 1995;80(3):389-99. https://doi.org/10.1016/0092-8674(95)90489-1

50. Park S, Lee J, Ko YH, Han A, Jun HJ, Lee SC, et al. The impact of Epstein-Barr virus status on clinical outcome in diffuse large B-cell lymphoma. Blood. 2007;110(3):972-8. https://doi.org/10.1182/ blood-2007-01-067769

51. Kulwichit W, Edwards RH, Davenport EM, Baskar JF, Godfrey V. Raab-Traub N. Expression of the Epstein-Barr virus latent membrane protein 1 induces B cell lymphoma in transgenic mice. Proc Natl Acad Sci U S A. 1998;95(20):11963-8. https://doi.org/10.1073/pnas.95.20.11963

52. Gires O, Zimber-Strobl U, Gonnella R, Ueffing M, Marschall G, Zeidler R, et al. Latent membrane protein 1 of Epstein-Barr virus mimics a constitutively active receptor molecule. Embo J. 1997;16(20):6131-40. https://doi.org/10.1093/emboj/16.20.6131

53. Dawson CW, Tramountanis G, Eliopoulos AG, Young LS. Epstein-Barr virus latent membrane protein 1 (LMP1) activates the phosphatidylinositol 3-kinase/Akt pathway to promote cell survival and induce actin filament remodeling. J Biol Chem. 2003;278(6):3694-704. https://doi.org/10.1074/jbc. M209840200

54. Kingma DW, Weiss WB, Jaffe ES, Kumar S, Frekko K, Raffeld M. Epstein-Barr virus latent membrane protein-1 oncogene deletions: correlations with malignancy in Epstein-Barr virus--associated lymphoproliferative disorders and malignant lymphomas. Blood. 1996;88(1):242-51.https://doi. org/10.1182/blood.V88.1.242.242

55. Yoon H, Park S, Ju H, Ha SY, Sohn I, Jo J, et al. Integrated copy number and gene expression profiling analysis of Epstein-Barr virus-positive diffuse large B-cell lymphoma. Genes Chromosomes Cancer. 2015;54(6):383-96. https://doi.org/10.1002/gcc.22249

56. Kataoka K, Miyoshi H, Sakata S, Dobashi A, Couronné L, Kogure Y, et al. Frequent structural variations involving programmed death ligands in Epstein-Barr virus-associated lymphomas. Leukemia. 2019;33(7):1687-99. https://doi.org/10.1038/s41375-019-0380-5

57. Kato H, Karube K, Yamamoto K, Takizawa J, Tsuzuki S, Yatabe Y, et al. Gene expression profiling of Epstein-Barr virus-positive diffuse large B-cell lymphoma of the elderly reveals alterations of characteristic oncogenetic pathways. Cancer Sci. 2014;105(5):537-44. https://doi.org/10.1111/cas.12389

58. Gebauer N, Gebauer J, Hardel TT, Bernard V, Biersack H, Lehnert H, et al. Prevalence of targetable oncogenic mutations and genomic alterations in Epstein-Barr virus-associated diffuse large B-cell lymphoma of the elderly. Leuk Lymphoma. 2015;56(4):1100-6. https://doi.org/10.3109/10428194.2014.944522 
59. Hofscheier A, Ponciano A, Bonzheim I, Adam P, Lome-Maldonado C, Vela T, et al. Geographic variation in the prevalence of Epstein-Barr virus-positive diffuse large B-cell lymphoma of the elderly: a comparative analysis of a Mexican and a German population. Mod Pathol. 2011;24(8):1046-54. https://doi.org/10.1038/modpathol.2011.62

60. Tracy SI, Habermann TM, Feldman AL, Maurer MJ, Dogan A, Perepu US, et al. Outcomes among North American patients with diffuse large B-cell lymphoma are independent of tumor EpsteinBarr virus positivity or immunosuppression. Haematologica. 2018;103(2):297-303. https://doi. org/10.3324/haematol.2017.176511

61. Hans CP, Weisenburger DD, Greiner TC, Gascoyne RD, Delabie J, Ott G, et al. Confirmation of the molecular classification of diffuse large B-cell lymphoma by immunohistochemistry using a tissue microarray. Blood. 2004;103(1):275-82. https://doi.org/10.1182/blood-2003-05-1545

62. Mareschal S, Lanic H, Ruminy P, Bastard C, Tilly H, Jardin F. The proportion of activated B-cell like subtype among de novo diffuse large B-cell lymphoma increases with age. Haematologica. 2011;96(12):1888-90. https://doi.org/10.3324/haematol.2011.050617

63. Klapper W, Kreuz M, Kohler CW, Burkhardt B, Szczepanowski M, Salaverria I, et al. Patient age at diagnosis is associated with the molecular characteristics of diffuse large B-cell lymphoma. Blood. 2012;119(8):1882-7. https://doi.org/10.1182/blood-2011-10-388470

64. Asano N, Yamamoto K, Tamaru J, Oyama T, Ishida F, Ohshima K, et al. Age-related Epstein-Barr virus (EBV)-associated B-cell lymphoproliferative disorders: comparison with EBV-positive classic Hodgkin lymphoma in elderly patients. Blood. 2009;113(12):2629-36. https://doi.org/10.1182/ blood-2008-06-164806

65. Ohashi A, Kato S, Okamoto A, Inaguma Y, Satou A, Tsuzuki T, et al. Reappraisal of Epstein-Barr virus (EBV) in diffuse large B-cell lymphoma (DLBCL): comparative analysis between EBV-positive and EBV-negative DLBCL with EBV-positive bystander cells. Histopathology. 2017;71(1):89-97. https:// doi.org/10.1111/his.13197

66. Okamoto A, Yanada M, Inaguma Y, Tokuda M, Morishima S, Kanie T, et al. The prognostic significance of EBV DNA load and EBER status in diagnostic specimens from diffuse large B-cell lymphoma patients. Hematol Oncol. 2017;35(1):87-93. https://doi.org/10.1002/hon.2245

67. Hoeller S, Tzankov A, Pileri SA, Went P, Dirnhofer S. Epstein-Barr virus-positive diffuse large B-cell lymphoma in elderly patients is rare in Western populations. Hum Pathol. 2010;41(3):352-7. https:// doi.org/10.1016/j.humpath.2009.07.024

68. Beltran BE, Castillo JJ, Morales D, de Mendoza FH, Quinones P, Miranda RN, et al. EBV-positive diffuse large B-cell lymphoma of the elderly: a case series from Peru. Am J Hematol. 2011;86(8):663-7. https://doi.org/10.1002/ajh.22078

69. Uccini S, Al-Jadiry MF, Scarpino S, Ferraro D, Alsaadawi AR, Al-Darraji AF, et al. Epstein-Barr viruspositive diffuse large B-cell lymphoma in children: a disease reminiscent of Epstein-Barr viruspositive diffuse large B-cell lymphoma of the elderly. Hum Pathol. 2015;46(5):716-24. https://doi. org/10.1016/j.humpath.2015.01.011

70. Hu S, Xu-Monette ZY, Balasubramanyam A. Manyam GC, Visco C, Tzankov A, et al. CD30 expression defines a novel subgroup of diffuse large B-cell lymphoma with favorable prognosis and distinct gene expression signature: a report from the International DLBCL Rituximab-CHOP Consortium Program Study. Blood. 2013;121(14):2715-24. https://doi.org/10.1182/blood-2012-10-461848

71. Tokuyama K, Okada F, Sato H, Matsumoto S, Matsumoto A, Haruno A, et al. Computed tomography findings in Epstein-Barr virus (EBV)-positive diffuse large B-cell lymphoma (DLBCL) of the elderly: comparison with EBV-negative DLBCL. Br J Radiol. 2017;90(1072):20160879. https://doi. org/10.1259/bjr.20160879

72. Coiffier B, Lepage E, Briere J, Herbrecht R, Tilly H, Bouabdallah R, et al. CHOP chemotherapy plus rituximab compared with $\mathrm{CHOP}$ alone in elderly patients with diffuse large-B-cell lymphoma. N Engl J Med. 2002;346(4):235-42. https://doi.org/10.1056/NEJMoa011795

73. Miller TP, Dahlberg S, Cassady JR, Adelstein DJ, Spier CM, Grogan TM, et al. Chemotherapy alone compared with chemotherapy plus radiotherapy for localized intermediate- and high-grade non-Hodgkin's lymphoma. N Engl J Med. 1998;339(1):21-6. https://doi.org/10.1056/NEJM199807023390104

74. Poeschel V, Held G, Ziepert M, Witzens-Harig M, Holte H, Thurner L, et al. Four versus six cycles of CHOP chemotherapy in combination with six applications of rituximab in patients with aggressive 
B-cell lymphoma with favourable prognosis (FLYER): a randomised, phase 3, non-inferiority trial. Lancet. 2019;394(10216):2271-81. https://doi.org/10.1016/S0140-6736(19)33008-9

75. Stephens DM, Li H, Leblanc ML, Puvvada SD, Persky D, Friedberg J W., et al. Continued Risk of Relapse Independent of Treatment Modality in Limited-Stage Diffuse Large B-Cell Lymphoma: Final and LongTerm Analysis of Southwest Oncology Group Study S8736. J Clin Oncol. 2016;34(25):2997-3004. https://doi.org/10.1200/JCO.2015.65.4582

76. Pfreundschuh M, Schubert J, Ziepert M, Schmits R, Mohren M, Lengfelder E, et al. Six versus eight cycles of bi-weekly CHOP-14 with or without rituximab in elderly patients with aggressive CD20+ B-cell lymphomas: a randomised controlled trial (RICOVER-60). Lancet Oncol. 2008;9(2):105-16. https://doi.org/10.1016/S1470-2045(08)70002-0

77. Sehn LH, Congiu AG, Culligan DJ, Gironella M, Yoon DH, Ogura M et al. No Added Benefit of Eight Versus Six Cycles of CHOP When Combined with Rituximab in Previously Untreated Diffuse Large B-Cell Lymphoma Patients: Results from the International Phase III GOYA Study. Blood. 2018;132(Supplement 1):783. https://doi.org/10.1182/blood-2018-99-116845

78. Feugier P, Van Hoof A, Sebban C, Solal-Celigny P, Bouabdallah R, Ferme C, et al. Long-term results of the R-CHOP study in the treatment of elderly patients with diffuse large B-cell lymphoma: a study by the Groupe d'Etude des Lymphomes de l'Adulte. J Clin Oncol. 2005;23(18):4117-26. https://doi. org/10.1200/JCO.2005.09.131

79. Battle-Lopez A, de Villambrosia SG, Nuñez J, Cagigal ML, Montes-Moreno S, Conde E., et al. EpsteinBarr virus-associated diffuse large B-cell lymphoma: diagnosis, difficulties and therapeutic options. Expert Rev Anticancer Ther. 2016;16(4):411-21. https://doi.org/10.1586/14737140.2016.1149065 